\title{
Analysis of the Development and Demonstration of Moral Education in the Music Teaching of Vocational Colleges
}

\author{
Tian Qian \\ Xi'an Aeronautical Polytechnic Institute; Xi'an 710089 China
}

\begin{abstract}
Keywords: music teaching of vocational colleges; moral education; moral education penetration; approaches; methods.
\end{abstract}

\begin{abstract}
The increasing development of society has made higher and higher requirements with talents' comprehensive development and quality education, while quality education needs long-term development and to be performed from the kindergarten. Thus, someone put forward that moral education can be penetrated into the music teaching of vocational colleges, which is a magnificent project. In order to achieve this concept, it requires that music teachers of vocational colleges should regard the core quality development of students as the target and launch practical research to push the quality enhancing and effect strengthening of education and teaching. In addition, specific experiences and results on moral courses construction should be researched to make beneficial exploration with the penetration of moral education into the music teaching of vocational colleges.
\end{abstract}

\section{Introduction}

In modern society, living quality is constantly developing and talents are required to get comprehensive development. Moral education is particularly significant. Such education is a process with long-term development. And these opinions about moral education should be infiltrated into children's education to train comprehensive talents with sound personality. The best method to implement such concept is to integrate moral education with music of vocational colleges, having infiltrated effect on students, naturally affected their moral standards and led to correct opinions. It lays a foundation for the future society training talents. This paper is to discuss the problem that how to infiltrate moral education into the music of vocational colleges and what those people devoted to music education in vocational colleges should do and which ideological method they should choose to integrate moral education and music education. All these problems and thinking are the severe test facing most music teachers of vocational colleges.

Teaching stage in vocational colleges is one significant period for a person' mental and physic development where they will be deeply affected through the knowledge infusion. At the same time, this stage is the beginning period in which a person's outlook on life and value is formed. Implementing moral education from this stage can correctly establish a person's three outlooks. Therefore, it is especially significant that how to infiltrate moral education into the music of vocational colleges.

\section{It is Very Important for Vocational College Music Educators to Cultivate the Awareness of Moral Education}

China's education teaching level has been improved to a certain extent along with the continuous advancement of the national education reform system. Music teaching has been more and more popular among people. It is not only related to the development of national music cause, but also plays a rather large role in rendering people's ideological culture. Under the social background with gradual deepening diversified development, contemporary higher vocational students are affected and eroded by the culture from other countries, which has gradually reduced their national culture awareness. It has bad effects on the further advancement of Chinese development and construction. It has become particularly significant that how to deepen moral education music in the teaching process aiming at students' development characteristics. Thus, this paper will take it as the main 
content of the explanation and give specific teaching strategies for references through the analysis with current situation of moral education in music teaching.

Moral education in music teaching is the significant content in the music teaching of secondary vocational colleges. Its implementation can not only promote the further inheriting of national traditional culture but cultivate students' taste to have a positive effect on enhancing their comprehensive qualities. However, from the current situation of moral education implementation in secondary vocational music teaching, its implementation efficiency is relatively low. And there exists the phenomenon of insufficient understanding and low study interest of students. Therefore, it has become the primary task in the process of music teaching of secondary vocational colleges that

how to adopt appropriate teaching strategies, improve students' learning efficiencies and promote the deepening of moral education in music teaching.

Why must moral education be infiltrated in vocational colleges music? Because music learning and moral education have a certain relationship and there is no sense of dissonance. Being able to dig out moral education from music teaching requires that music educators should constantly promote their abilities and find the potential moral education to make better rendering and add some related moral education types. Ability quality is vital for vocational college educators. At first, they should have the awareness of moral education so that they can correctly guide students' patriotism and three outlooks and help students cultivate the feelings of moral education since the childhood. The stronger the moral foundation of music educators in vocational colleges, the better they can infiltrate moral education into music textbooks. Therefore, music teachers in vocational colleges should keep improving themselves so as to the content of moral education is familiar to them.

Music teachers can also play musicals related with moral education. Students can study and watch the musicals at the same time. Such method can make the picture reflected in front of students so that they have a deeper understanding with the music and arouse strong patriotic feelings. Especially in the teaching stage of vocational colleges, students' three outlooks have not been formed yet. And at this time, students have fast physical and mental development and strong ability to absorb new concepts. It can not only enable students to learn the knowledge and new words of music teaching content but also infiltrate the patriotic feelings of moral education. And they will forever keep the concept of "never forget the national humiliation and revitalize China" in their minds, which will also have a good impact on their future. A person with feelings of national honor and humiliation must be a principled person in the future. So it can be seen that this education case is a success.

Interest is the best teacher for students. In order to infiltrate national music in the process of secondary vocational students learning music, teachers should enhance students' learning interests. Teachers should be able to start from the characteristics of students' development, combine with the development background of the era and effectively attract students' attention in the specific work process. Or they can start with the real life of the students. Students tend to be more interested in things that are close to their own lives. For instance, when explaining the relevant content of "Zou Xi Kou", students will be disgusted if such music theme is shown to them directly. In order to improve students' interest in learning, teachers can start with Gong Linna who sung this song and use new and advanced technology such as computer technology to attract students' attention. It is suitable for their age and growth characteristics. Then the works can be introduced to enhance students' interest in learning and improve the efficiency of classroom teaching. And the historical background and story included in "Zou Xi Kou" can be introduced into the classroom, which can not only attract students but have a positive effect on the connotation appreciation of music. It is beneficial to improve the teaching quality of national music.

\section{Create a Good Learning Environment That Can Stimulate Students' Interest in Learning}

In order to promote students to have a further understanding with moral education in music teaching, generate their positive interest in learning and achieve teaching objectives, the related work of excavating the connotation of works should be strengthened in the teaching process. And teachers should make the relevant content clear and understood before class and search the background and stories that they haven't mastered so that teachers can introduce such background in the teaching 
process to guide students to experience the joys and sorrows in music and life feeling, go deep into the author's context and feel its beauty. It is conducive to promoting students' deep understanding of music works connotation, improving learning efficiency and enhancing their patriotic feelings.

From the current development situation of moral education in music teaching of secondary vocational music teaching, there exists many insufficiencies in the process of implementation, causing the rather low teaching efficiency and quality. While from the perspective of students, students hardly have access to moral education music in the daily music learning. They seem to have little understanding with moral education music and they almost think there is no place for such kind of music. In terms of secondary vocational students themselves, they are often interested in the snackstyle popular music due to the environmental impact and their own poor binding, which is also one of the main factors leading to the neglect with moral education music. But what is shown behind moral education music is often a music quality with historical and cultural connotation. It is difficult for secondary vocational students to raise a higher interest in learning, and their cultural literacy is relatively low. So it is difficult for them to effectively understand the connotation behind the moral education music and appreciate it, resulting in their relatively low learning efficiency.

It is also a good way to mix emotions with scenery and a good prospect will better guide students. In the music teaching content of vocational colleges, most music has a large number of scene descriptions. The concept of vocational college students has not been fully formed, so it is easy for them to be integrated into the context of music teaching content. At this time, music educators in vocational colleges can let students close their eyes and vividly read the teaching content of music to let them imagine in their minds and immersed into the picture depicted by music teaching content so as to enhance the appeal and make the expression of music teaching content more intuitive.

To promote the improvement of national music teaching quality and deepen students' understanding of their learning content, it is also needed that setting up certain situation teaching to let students be personally on the scene and deepen the feeling with national music. Teachers can create the national music learning atmosphere for students in the specific work process. For example: for appreciating some ethnic minority music, teachers can can apply computer technology to manifest the folk costumes and culture related with music through the form of pictures or videos to let students understand the connotation of national music. When teaching The Moon Reflected in the Twin Ponds, teachers can introduce the life experience of music player, Hua Yanjun, to students and let students have dense interest in national music and deepen the appreciation feeling with music in the combination with its background so as to improve the classroom teaching efficiency.

\section{Classroom Interaction and Communication}

Music educators in vocational colleges should not only teach students the contents of classroom knowledge, but also interact with students to mobilize the active atmosphere of class. Some of the lessons should not be given directly to students but left to them to discover by themselves. First of all, students should be encouraged to raise their hands and express their ideas. And teachers should point out the shortcomings and revise them after listening to students' speech, touching their hearts and make them understand the reason to make the music knowledge and moral education knowledge that vocational college students should understand deeply rooted in their minds.

From the perspective of teachers, moral education in music teaching has some problems in the current development situation of music teaching in secondary vocational schools. Teachers usually fail to realize the importance of moral education in music teaching and often neglect the teaching of this content. And teachers cannot understand the spiritual development of contemporary students, have high music cognitive level and thoroughly master and analyze the connotation and form of moral education music works in the process of teaching moral education content. In addition, the traditional teaching method is adopted to implement the curriculum. Boring teaching content can easily make students lose learning interest and reduce learning efficiency. Meanwhile, teachers cannot take the knowledge level of students into consider station and make deep excavation with the ideological connotation of moral education music works in the teaching process. They just make the infusion exchange according to the textbooks, leading to a rather low teaching efficiency. 


\section{How Can Music Teachers in Vocational Colleges Make Beneficial Exploration Through Infiltrating Moral Education into Music Teaching for Beneficial Exploration}

Traditional methods of infiltrating moral education into music teaching are as above. And the new methods should be constantly researched by every music educators through the process of practice. It is a magnificent project and it can only be done through the cooperation of students, music educators of vocational college and students' families.

\section{Conclusion}

It can be seen from the above contents that this discipline, music, has the following characteristics: humanity, thought and knowledge. There is an inseparable link between the education course of music discipline in vocational colleges and the research of moral education. They are intertwined, confined and affected each other. The staff of music education in vocational colleges should lay a good foundation for their own moral education, which can help them better teach students what moral education is, establish the correct outlook of students on life and values, set up the patriotic feelings of the students and make them positive. Moral education is a course aimed at cultivating students' core qualities, which requires that music teachers in vocational colleges conduct practical research so as to promote the quality and efficiency of education teaching. Design distinctive and interesting courses to realize the purpose of infiltrating education in this paper and guide students to set firm goals for their future and make unremitting efforts.

\section{References}

[1]. Qing Zhu. The Way and Method of Moral Education Infiltrated in the Music Teaching of Vocational Colleges[D]. Shanghai Normal University,2015.

[2]. Jie Sun. Discussion on the Way and Method of Moral Education Infiltrated in the Music Teaching of Vocational Colleges[J]. New Courses (Vocational colleges),2015, (01):163.

[3]. Yunzhi Chen. The Way and Method of Moral Education Infiltrated in the Music Teaching of Vocational Colleges[J]. Course education research, 2015, (11):41.

[4]. Hongmei Zhu. The Way and Method of Moral Education Infiltrated in the Music Teaching of Vocational Colleges[J]. Success (Education),2016, (01):249.

[5]. Guihong Lu. The Way and Method of Moral Education Infiltrated in the Music Teaching of Vocational Colleges[J]. Course education research,2015, (26):57.

[6]. Lixia Zhang and Yanfang Wang. The Way and Method of Moral Education Infiltrated in the Music Teaching of Vocational Colleges[J]. Chinese Extra-school Education, 2016, (05):119+129.

[7]. Bing Huang. Discussion on the Way and Method of Moral Education Infiltrated in the Music Teaching of Vocational Colleges[J]. China Youth,2016, (28):66. 